\title{
Three Column Stabilization Through Posterior Approach Alone: Transpedicular Placement of Distractable Cage With Transpedicular Screw Fixation
}

\author{
Giyas Ayberk, Mehmet Faik Ozveren, Naci Altundal, Hakan TOsun, \\ Zekai SECKIN, Kasim KILICARSLAN*, and Metin KAPLAN** \\ Departments of Neurosurgery and * Orthopedics, Ankara Ataturk Training and \\ Research Hospital, Ankara, Turkey; ${ }^{* *}$ Department of Neurosurgery, \\ School of Medicine, Firat University, Elazig, Turkey
}

\begin{abstract}
The combination of anterior and posterior instrumentation provides the most stable repair for burst fractures of the thoracolumbar spine. However, the use of both approaches on a trauma patient may increase morbidity. Stabilization of three columns through only one approach can provide an effective outcome. We treated eight patients with burst fracture involving the thoracic or lumbar vertebrae by the application of anterior and posterior stabilization instruments through only the posterior approach. The desired stabilization was obtained in all patients. The advantages are the absence of the risks of the anterior approach, facilitation of the placement of anterior and posterior stabilization devices through only one approach, preserving the unity of the anterior longitudinal ligament, the effect of the anterior corpus in preventing displacement of the cage, application of compression on the pedicle screw system to both decrease the kyphosis angulation due to collapse of vertebra and to help the stabilization of the cage, repair of the dural tears at the posterior side, prevention of cage displacement by distraction and thus leaning on the endplates, and ease of performance by a neurosurgeon alone.
\end{abstract}

Key words: corpectomy, intercorporal distractable cage, posterior approach

\section{Introduction}

Burst fractures occur as a result of an axial load on the vertebral column after trauma causing displacement of the middle column into the vertebral canal and reduction of the diameter of the vertebral canal bony elements. The most effective treatment for this type of injury is vertebral canal decompression and stabilization of the vertebral column through an anterior approach. ${ }^{12,13)}$ The second choice of surgical treatment is combined anterior and posterior approaches. ${ }^{2,15,20)}$ The third option is only posterior instrumentation, particularly if the posterior longitudinal ligament has remained intact. ${ }^{2,29)}$ However, this technique is associated with considerable loss of correction and anterior fusion cannot be reliably achieved. ${ }^{14)}$ Removal of the compressing bone on the anterior side of the spinal cord directly addresses the pathology. ${ }^{2)}$ Ligamentotaxis is recom-

Received February 21, 2007; Accepted October 29, 2007 mended to decrease anterior compression during the posterior stabilization, if the posterior longitudinal ligament is intact. ${ }^{20}$ Therefore, reduction of the anterior compression is necessary to achieve an uncompromised spinal cord after burst fracture.

There are two options for the combined surgery, anterolateral and separate anterior and posterior stabilizations. In the anterolateral approach, the lateral abdomen and/or thorax are obliquely opened and stabilization devices applied through this opening after corpectomy. ${ }^{24)}$ The corpectomy defect is replaced with a bone graft or intercorporal cage and the second stabilization is obtained with a laterally applied Kaneda construct fixation system. ${ }^{24)}$ Alternatively, pedicle screw insertion is first performed through the posterior approach, followed by the anterior approach in a second operative session. ${ }^{20)}$ Although the biomechanical and decompressive goals can be obtained satisfactorily by both of these two management strategies, the morbidity risk of anterolateral opening is higher than that of the posterior pedicle screw approach. ${ }^{15,20)}$ Recently, an- 
Table 1 Preoperative findings from radiography, computed tomography, and magnetic resonance imaging

\begin{tabular}{|c|c|c|c|c|c|c|c|c|c|}
\hline $\begin{array}{c}\text { Case } \\
\text { No. }\end{array}$ & $\begin{array}{l}\text { Fracture } \\
\text { site }\end{array}$ & $\begin{array}{c}\text { Canal } \\
\text { compromise } \\
(\%)\end{array}$ & $\begin{array}{l}\text { Height } \\
\text { loss } \\
(\%)\end{array}$ & $\begin{array}{l}\text { Scoliotic } \\
\text { angle } \\
\text { (degree) }\end{array}$ & $\begin{array}{c}\text { Sagittal } \\
\text { index } \\
\text { (degree) }\end{array}$ & $\begin{array}{c}\text { Migration of } \\
\text { intervertebral } \\
\text { disc into } \\
\text { the canal }\end{array}$ & PLL & ALL & $\begin{array}{c}\text { Posterior } \\
\text { column } \\
\text { involvement }\end{array}$ \\
\hline 2 & T9 & 80 & 50 & 10 & 20 & present & ruptured & intact & present \\
\hline 3 & L5 & 62 & 30 & 0 & 8 & absent & intact & intact & present \\
\hline 6 & $\mathrm{~T} 12$ & 66 & 60 & 5 & 31 & present & ruptured & intact & present \\
\hline 7 & L1 & 62 & 50 & 5 & 4 & absent & ruptured & intact & present \\
\hline 8 & L2 & 65 & 55 & 10 & 14 & absent & intact & intact & present \\
\hline
\end{tabular}

ALL: anterior longitudinal ligament, PLL: posterior longitudinal ligament.

Table 2 Clinical findings of the patients

\begin{tabular}{|c|c|c|c|c|}
\hline $\begin{array}{l}\text { Case } \\
\text { No. }\end{array}$ & $\begin{array}{c}\text { Age } \\
(\text { yrs)/ } \\
\text { Sex }\end{array}$ & $\begin{array}{l}\text { ASIA } \\
\text { score }\end{array}$ & $\begin{array}{c}\text { Additional } \\
\text { traumatic } \\
\text { injury }\end{array}$ & Type of accident \\
\hline 1 & $21 / \mathrm{M}$ & A & $\begin{array}{l}\text { bil calcaneus, } \\
\text { talus, pelvic, } \\
\text { and lt distal } \\
\text { radius fracture }\end{array}$ & fall from height \\
\hline 2 & $31 / \mathrm{M}$ & B & rt hemothorax & fall from height \\
\hline 3 & $17 / \mathrm{F}$ & $\mathrm{E}$ & $\begin{array}{l}\text { lt calcaneus } \\
\text { fracture }\end{array}$ & fall from height \\
\hline 4 & $20 / \mathrm{M}$ & $\mathrm{E}$ & absent & traffic accident \\
\hline 5 & $31 / \mathrm{M}$ & $\mathrm{E}$ & absent & fall from height \\
\hline 6 & $20 / \mathrm{M}$ & B & absent & traffic accident \\
\hline 7 & $20 / \mathrm{M}$ & B & absent & traffic accident \\
\hline 8 & $52 / \mathrm{M}$ & $\mathrm{E}$ & $\begin{array}{l}\text { bil calcaneus } \\
\text { fracture }\end{array}$ & fall from height \\
\hline
\end{tabular}

ASIA: American Spinal Injury Association.

terior corpectomy and distractable titanium cage implantation after posterior pedicle screw fixation has been reported for the treatment of unstable burst fractures. ${ }^{20)}$

Here, we report eight cases of burst fractures or fracture dislocations of the thoracic or lumbar spine treated through the posterior approach that involved fixation with both anterior and posterior stabilization devices.

\section{Materials and Methods}

Eight patients, seven men and one woman aged 17 to 52 years, with burst fractures, resulting from falls from heights in five patients and motor vehicle accidents in three, were admitted to the Department of Neurosurgery of Ataturk Training and Research Hospital between August 2006 and June 2007. All patients except two had neurologic deficits. Three patients had bilateral calcaneus fractures. The lum-
Table 3 American Spinal Injury Association scale for clinical evaluation of the patients

\begin{tabular}{cl}
\hline Grade & $\begin{array}{c}\text { Description of deficit } \\
\text { below the level of the lesion }\end{array}$ \\
\hline A & Complete: no motor or sensory function \\
B & Incomplete: sensory but no motor function \\
C & Incomplete: some motor functions preserved \\
& but most muscle groups < grade 3 \\
D & Incomplete: some motor functions preserved \\
& but most muscle groups > grade 3 \\
$\mathrm{E}$ & Normal sensory and motor functions \\
\hline
\end{tabular}

bar vertebrae were involved in six patients and the thoracic vertebrae in two. The percentage of canal compromise was measured with the formula of: $\mathrm{a}=$ $(1-x / y) \times 100$, where a, percentage of canal compromise; $x$, mid-sagittal diameter of spinal canal of the level of injury; and y, average mid-sagittal diameter of the spinal canal at the adjacent uninjured levels above and below the injured level. ${ }^{11)}$ The sagittal index was measured to quantify the local kyphosis angle. ${ }^{8)}$ The scoliotic angle was measured according to Ferguson's method. ${ }^{25)}$ The sagittal index was between $4-31^{\circ}$. The radiological and clinical data of the patients are given in Tables 1 and 2 . The results of neurological examination of the patients were evaluated according to the American Spinal Injury Association scale (Table 3).

\section{Systems used for stabilization}

Two types of intercorporal distractable cages were used for anterior stabilization: one type was 25 $\mathrm{mm}$ in height and $20 \mathrm{~mm}$ diameter (Tasarim Medikal, Istanbul, Turkey), and the second type was $25 \mathrm{~mm}$ in height and $18 \mathrm{~mm}$ in diameter (StrykerVLIFT; imported by Kayacan Group, Istanbul, Turkey). The first type was used in only one patient and 
the second type was used in the other seven patients. The polyaxial posterior pedicle screw system (Tasarim Medikal) was used for posterior stabilization.

\section{Operative technique}

All procedures were performed under general anesthesia in the prone position on a Cloward surgical saddle (Surgical Equipment International, Honolulu, Hawaii, U.S.A.) with C-armed scopy (Siemens Siremobil L, Muenchen, Germany). The lamina of the fractured corpus and the lamina of the upper corpus were removed through the posterior approach to expose the pedicles of the fractured vertebrae. Discectomies were performed at the upper and lower disc spaces of the fractured vertebra to expose the endplates of the upper and lower corpora (Fig. 1A, B). The transverse process of the fractured corpus was cut at its attachment to the pedicle. The transverse process of the fractured vertebra was not removed since this forms a protective barrier for the nerve root originating from the foramen between the upper and fractured corpora. The pedicles of the fractured corpus were removed totally. Through the gaps formed after pedicle resection, the posterior two thirds of the fractured vertebra corpus was totally evacuated with a high speed drill or ultrasonic bone curette and hand curettes, which eliminated the anterior compression on the dura. Approximately one third of the anterior part of the corpus was kept intact, but a space of the size of a distractable cage was formed within the corpus. The lateral compact bone of the corpus was also untouched. In particular, the superior and inferior endplates of the fractured corpus were removed to create enough space to settle the cage on the endplates of the neighboring vertebrae.

Pedicular screws were introduced into the upper and lower corpora to facilitate the entrance of the distractable cage by distraction of the screws. The distractable cage, in which the autogenous bone fragments were placed, was inserted into the corpus space through the resected pedicular space (Fig. 1C). The nerve root exiting through the inferior side of the involved corpus was protected from damage during placement of the cage. Generally, the cage could be introduced with a small amount of distraction applied on the pedicular screws on the cross side of the entrance side of the cage. Then, the cage was opened for settling on the superior endplate of the lower vertebra and the inferior endplate of the upper vertebra. The distraction of the cage was evaluated by radiography, and using a polyaxial pedicle screwrod system, the cage was fixed between the upper and lower pedicles with posterior stabilization sys-

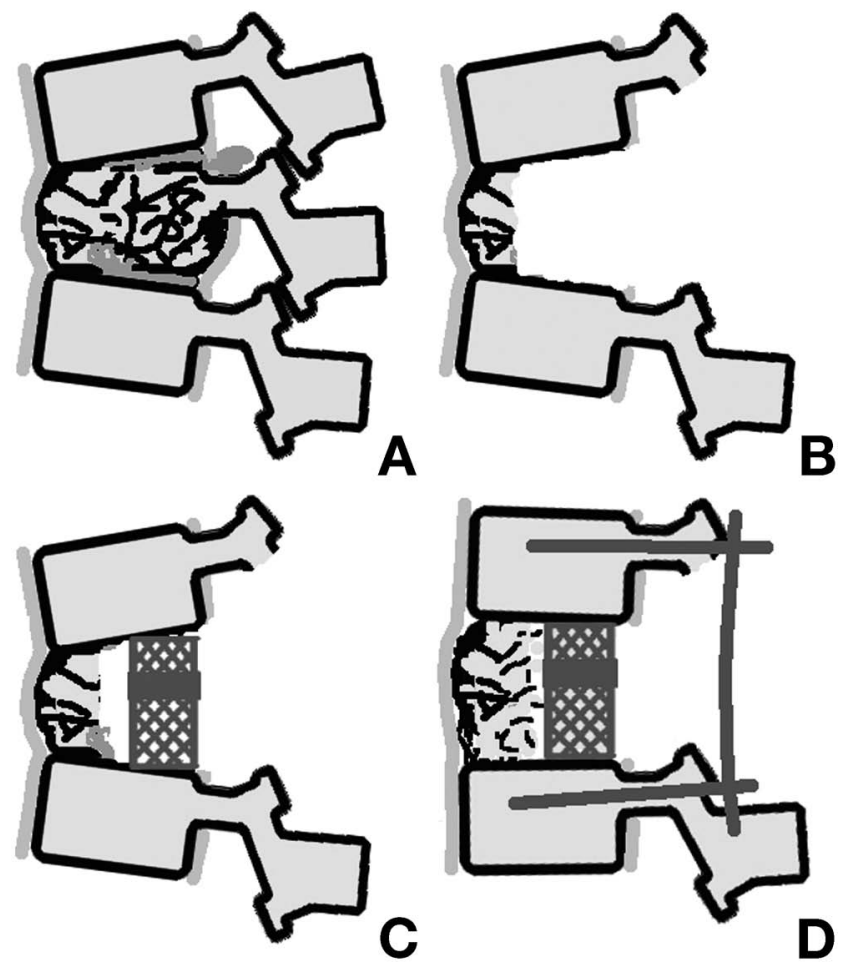

Fig. 1 Diagrams illustrating the procedure. A: Integrity of the vertebra corpus was destroyed by the burst fracture. B: Lamina of the fractured corpus and the lamina of the upper corpus were removed to expose the pedicles of the fractured vertebra and the disc levels above and below. Discectomies were performed at the upper and lower disc spaces to expose the endplates of the upper and lower corpora. C: Distractable cage, containing autogenous bone fragments, is inserted into the intercorporal space. D: Cage fixed between the upper and lower pedicles by the posterior stabilization system.

tem and compression was applied on the posterior system to better settle the cage (Fig. 1D). The bone fragments obtained were embedded in the posterolateral side of the vertebral column for posterolateral fusion.

\section{Results}

There was no difference between the preoperative and postoperative neurologic status of the patients. The average operative time was 6 hours. The average blood loss was 6 units of blood. All patients were mobilized with or without the use of arm cane support depending on the level of the spinal cord injury. 

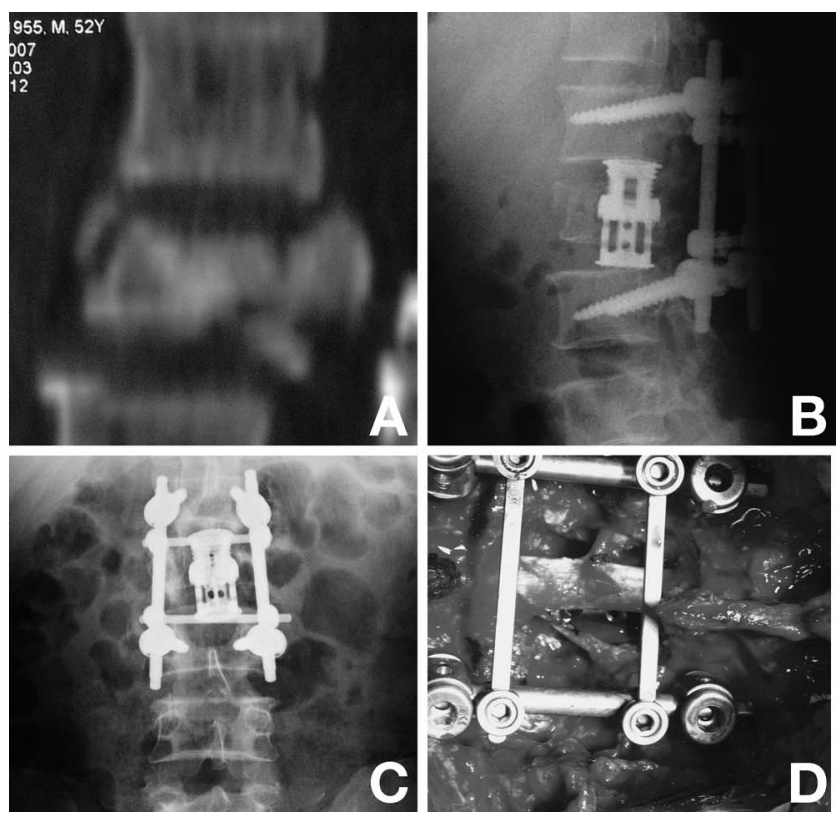

Fig. 2 Case 8. A 52-year-old male admitted to the hospital after a fall from 6 meters. A: Sagittal reconstructed computed tomography scan showing the burst fracture of the L2 vertebra. B, C: Postoperative lateral and anteroposterior radiographs showing the distracted cage behind the anterior one third of the remnant of the L2 vertebra body, well fixed by the pedicle screw system. D: Intraoperative photograph showing the L2 nerve roots were completely exposed after the pedicles of the fractured vertebra (L2) were removed.

The upper and lower surfaces of the cage were settled on the endplates of the superior and inferior vertebrae in six patients (Fig. 2). There was incomplete contact between the cage and endplate in two patients with L4 burst fractures (Fig. 3). Normal vertebral alignment was obtained in all patients. The follow-up period was 6 weeks to 10 months. There was no instrument insufficiency within this period.

\section{Discussion}

The combined anterior and posterior approach provides the most stable biomechanical repair for thoracolumbar vertebra traumas resulting in threecolumn demage..$^{2,14,15,19,20,24,28)}$ If the corpectomy defect is not reconstructed, $100 \%$ of the forces go through the posterior implant system. ${ }^{16)}$ Addition of a corpectomy cage to replace the fractured corpus significantly decreases the load over the posterior fixation system. ${ }^{14,16)}$ Three-column stabilization was

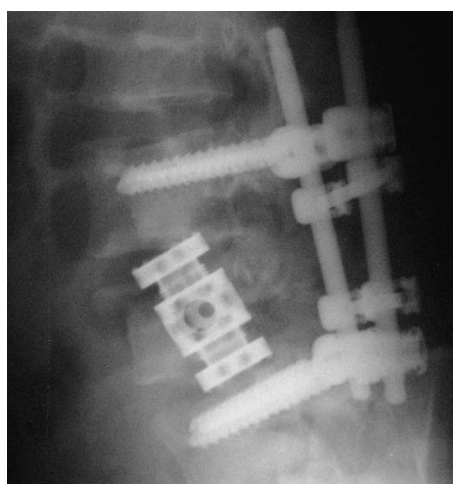

Fig. 3 Case 1. A 21-year-old male admitted to the hospital because of $\mathrm{L} 4$ burst fracture caused by a fall from 8 meters. Radiograph showing the distractable cage was fixed by the pedicle screw system. Although the cage was settled well on the endplate of the lower vertebra, there was incomplete contact between the cranial cage surface and the endplate of the upper vertebra. However, no instability signs of the system occurred in the 10 months following the operations.

obtained by this technique in all patients.

The interbody spinal distraction device is one of the repair methods used for the anterior stabilization of the vertebral column..$^{9,14,15,20,24,27,32)}$ Although intercorporal cage systems can be used alone, if placed in the intervertebral space, there is a risk of displacement of the vertebra or the device, known as polevaulting. Pole-vaulting can be defined as the sliding of the spine caused by effects of the ends leaning on the corpus, resulting in displacement of the graft and vertebra over time. ${ }^{3)}$ Thus, the best method is stabilization of the distraction device through anterior and, even better, posterior supports. ${ }^{3,28)}$ This procedure was achieved in our patients through posterior instrumentation.

The posterior approach to the thoracolumbar spine is very familiar to the neurosurgeon. In our all cases, to place the distractable cage from the posterior into the intercorporal space, the pedicle had to be removed totally to allow passage of the cage. The cage cannot be introduced into the intercorporal space without total excision of the pedicle. Posterior elements of the fractured vertebra were removed including all the base of the pedicle, exposing the entire spinal nerve root passing through the foramen (Fig. 2D). This is the foramen between the fractured and lower corpora. There was no risk of injury to the nerve root of the upper foramen since this nerve runs anteriorly to the intertransverse ligament. 
The anterior longitudinal ligament (ALL) is loose in the lumbar area and limits the vertebral extension movement. ${ }^{30)}$ In our approach, the ALL was not affected, and the anterior part of the corpus was preserved. This integrity provides two advantages. First, the intact ALL will form a protective band against hyperextension and rotation forces of the instrumented spine. ${ }^{10,31)}$ Second, anterior displacement of the distractable cage is prevented by preservation of the ALL and the anterior part of the fractured corpus in the original alignment.

The thoracolumbar spine can be approached anteriorly through thoracoabdominal, transperitoneal, or retroperitoneal routes. ${ }^{23)}$ The aorta generally bifurcates at the level of the L4 vertebral corpus into the common iliac arteries. ${ }^{23)}$ The segmental vessels require ligation to mobilize the aorta and vena cava to remove the collapsed vertebra body. Since the dominant feeding vessel, the Adamkiewicz artery, may originate anywhere from T5 to L5, ligation of this artery carries the risk of medulla spinalis infarction. ${ }^{23)}$ The reported incidence of all vascular complications with anterior lumbar spine surgery varies from $5 \%$ to $15 \% .^{1,4-6,18,22)}$ Complications include venous and arterial lacerations, and thromboembolic phenomena. ${ }^{6,22,24)}$ The lumbar plexus is formed within the psoas major muscle by the ventral rami of the L1 to L4 nerves. Femoral nerve and sympathetic plexus injury may result from retraction of the psoas major muscle or postoperative hematoma collection in the muscle. ${ }^{20,24)}$ Impotence and sterility, and bowel, urethra, and pancreas injuries have also been reported. ${ }^{4,22)}$ Since our patients were treated through posterior approach, none of these complications occurred.

The biomechanical stabilization of the present technique is debatable because of the anterolateral rod fixation and thus insufficient anterior fixation. Intercorporal cage devices used alone or combined with anterior or anterolateral rod fixation systems can provide desirable and reliable clinical and radiological outcomes. ${ }^{14,31)}$ The anterior distractable cage was introduced to correct anterior and middle column stability. Compression of the cage by the posterior system stabilized the cage against extension forces and decreased the load exerted on the pedicle screws. To achieve bone fusion, autogenous bone grafts were placed into the cage as well as into the posterolateral space for fusion.

A similar technique using the posterior approach has been described for spinal tumor resection. ${ }^{26)}$ The titanium cylinder cage filled the hole of the resected vertebra as in our case. ${ }^{17)}$ The vertebral body is removed totally by separating the ALL from the pleura. ${ }^{17)}$ It may be possible to dissect away the weakened pathological tissues from the anteriorly located vascular structures in tumor cases. However, surgical intervention in the area of the ALL would be dangerous in trauma cases, especially if surgeon is working at the posterior side of the spine. Therefore, we preserved the anterior part of the fractured corpus.

Recently, a similar technique has been used in two operative sessions. The pedicle screws were introduced first, and then the anterior distractable cage 7-10 days later. The cage was distracted until the plates settled on the endplates of the upper and lower corpora. ${ }^{20)}$ We obtained similar fixation through first expansion of the anterior cage and second compression of the posterior system. Our technique has some advantages compared to the twostage approach. First, we have seen no complication following the anterior approach. Second, compression of the pedicle screw system helped in the correction of the kyphosis angulation developed after the collapse of the vertebra. Third, every neurosurgeon familiar with spinal operations can perform the operation without the need for a thoracic or general surgeon.

The surface of the cage and endplates must be in contact throughout the surface area both for sharing the load on the cage and for bone fusion. However, lumbar lordosis caused cage settlement problems on the lower lumbar region in two of our patients. However, this incomplete contact surface affected only one side of the change in both cases. Compression through the pedicle screws on the upper and lower vertebrae caused to complete contact of the endplates and cage tips as well as correcting the kyphotic angulation of the spine, since the compression of the pedicle screw system is a maneuver causing lordotic position of the spine. Therefore, the radiological result of the instrumentation was better in patients with kyphotic angulation as in the lower lumbar region in our two patients.

Dural lacerations associated with laminar fractures occur in $32 \%$ of burst fractures. ${ }^{21)}$ Thus, posterior exploration for repairing of dural laceration before any attempt at spinal reduction is recommended. ${ }^{7)}$ The technique described here also provides this object.

The present approach provides the desired outcome due to the following advantages: Absence of risks carried by the anterior approach, facilitation of the placement of anterior and posterior fixation devices using only one approach, preservation of the unity of the ALL, effect of anterior corpus in preventing displacement of the cage, application of compression on the posterior pedicle system, prevention of cage displacement by distraction and 
thus leaning on endplates, repair of dural tears at the posterior side, and ease of performance by the neurosurgeon.

\section{References}

1) Baker JK, Reardon PR, Reardon MJ, Heggeness $\mathrm{MH}$ : Vascular injury in anterior lumbar spine surgery. Spine 18: 2227-2230, 1993

2) Been HD, Bouma GJ: Comparison of two types of surgery for thoracolumbar burst fractures: combined anterior and posterior stabilization vs. posterior instrumentation only. Acta Neurochir (Wien) 141: 349-357, 1999

3) Benzel EC: [Biomechanics of Spine Stabilization, ed 1]. Istanbul, Tunc Ofset Matbaacilik Tic ve San Ltd Sti, 1998, p 185 (Tur)

4) Bianchi C, Ballard JL, Abou-Zamzam AM, Teruya TH, Abu-Assal ML: Anterior retroperitoneal lumbosacral spine exposure: operative technique and results. Ann Vasc Surg 17: 137-142, 2003

5) Brau SA: Mini-open approach to the spine for anterior lumbar interbody fusion: description of the procedure, results and complications. Spine $J 2$ : 216-223, 2002

6) Brau SA, Delamarter RB, Schiffman ML, Williams LA, Watkins RG: Left iliac artery thrombosis during anterior lumbar surgery. Ann Vasc Surg 18: 48-51, 2004

7) Denis F, Burkus K: Diagnosis and treatment of cauda equina entrapment in the vertical lamina fracture of lumbar burst fracture. Spine 16: S433, 1991

8) Farcy JP, Weidenbaum M, Glassman SD: Sagittal index in management of thoracolumbar burst fracture. Spine 15: 958-965, 1990

9) Fourney DR, Gokaslan ZL: Spinal instability and deformity due to neoplastic conditions. Neurosurg Focus 14: E8, 2003

10) Harrop JS, Vaccaro AR, Foley KT, Kafkas I: Trauma surgery: thoracic and thoracolumbar spine, in Benzel EC (ed): [Spine Surgery: Techniques, Complication Avoidance and Management, ed 2]. Pennsylvania, Elsevier Churchill Livingstone, 2005, pp 544-562

11) Hashimoto $T$, Kaneda K, Abumi K: Relationship between traumatic spinal canal stenosis and neurologic deficits in thoracolumbar burst fractures. Spine 13: 1268-1272, 1988

12) Kaneda K, Abumi K, Fujiya M: Burst fractures with neurologic deficits of the thoracolumbar-lumbar spine. Results of anterior decompression and stabilization with anterior instrumentation. Spine 9: 788-795, 1984

13) Kaneda K, Taneichi H, Abumi K, Hashimoto T, Satoh S, Fujiya M: Anterior decompression and stabilization with Kaneda device for thoracolumbar burst fractures associated with neurologic deficits. J Bone Joint Surg Am 19: 69-84, 1997

14) Knop C, Lange U, Bastian L, Blauth M: Three-dimensional motion analysis with Syntex. Eur Spine J 9:
472-485, 2000

15) Korovessis P, Baikousis A, Zacharatos S, Petsinis G, Koureas G, Ililopoulos P: Combined anterior plus posterior stabilization versus posterior short segment instrumentation and fusion for mid-lumbar (L2-L4) burst fractures. Spine 31: 859-868, 2006

16) Lowery GL, Harms J: Principles of load sharing, in Bridwell KH, DeWald RL (eds): The Textbook of Spinal Surgery, ed 2. Washington, Lippincott-Raven, 1997, pp 155-165

17) Murakami H, Kawahara N, Abdel-Wanis ME, Tomita K: Total en bloc spondylectomy. Semin Musculoskelet Radiol 5: 189-194, 2001

18) Oskouian RJ Jr, Johnson JP: Vascular complications in anterior thoracolumbar spinal reconstruction. J Neurosurg 96(1 Suppl): 1-5, 2002

19) Oxland TR, Lund T: Biomechanics of stand-alone cages and cages in combination with posterior fixation: a literature review. Eur Spine J 9 Suppl 1: S95-S101, 2000

20) Payer M: Unstable burst fractures of the thoraco-lumbar junction: treatment by posterior bisegmental correction/fixation and staged anterior corpectomy and titanium cage implantation. Acta Neurochir (Wien) 148: 299-306, 2006

21) Pickett J, Blumenkoph B: Dural lacerations and thoracolumbar fractures. J Spinal Disord 2: 99-103, 1989

22) Rajarman V, Vingan R, Roth P, Heary RF, Conklin L, Jacobs GB: Visceral and vascular complications resulting from anterior lumbar interbody fusion. J Neurosurg 91(1 Suppl): 60-64, 1999

23) Rao RD, Singhal P: Chapter 9: Complications of anterior and posterior open approaches to the lumbar spine, in An HS, Jenis LG (eds): Complications of Spine Surgery, Treatment and Prevention. Philadelphia, Lippincott Williams \& Wilkins, 2006, pp 79-86

24) Rauzzino MJ, Shaffray CI, Nockels RP, Wiggins GC, Rock J, Wagner J: Anterior lumbar fusion with titanium threaded and mesh interbody cages. Neurosurg Focus 7: e7, 1999

25) Robinson EF, Wade WD: Statistical assessment of two methods of measuring scoliosis before treatment. Can Med Assoc J 129: 839-841, 1983

26) Tomita K, Toribatake Y, Kawahara N, Ohnari H, Kose H: Total en bloc spondylectomy and circumspinal decompression for solitary spinal metastasis. Paraplegia 32: 36-46, 1994

27) Turkmen CS, Ziyal IM, Dalbayrak S: Reconstruction of the thoracal spine with an anterior interbody fixator and methylmethacrylate. Technical note and case report. J Neurosurg 97(3 Suppl): 403-404, 2002

28) Vahldiek MJ, Panjabi MM: Stability potential of spinal instrumentations in tumor vertebral body replacement surgery. Spine 23: 543-550, 1998

29) Voranen MJ, Bostman OM, Myllynen P: Reduction of bone retropulsed into the spinal canal in thoracolumbar vertebral body compression burst fractures. Spine 20: 1699-1703, 1995 
30) Williams PL: Gray's Anatomy, ed 38. New York, Churchill Livingstone, 1995, p 446

31) Zdeblick TA, Phillips FM: Interbody cage devices. Spine 28(15 Suppl): S2-7, 2003

32) Zileli M, Kılıncer C: Clinical management in spinal cord tumors, in Zileli M, Ozer F (eds): [Surgery of Spine and Spinal Cord]. Izmir, META Basim, 2002, pp 1013-1050 (Tur)

Address reprint requests to: Giyas Ayberk, M.D., Department of Neurosurgery, Ankara Ataturk Training and Research Hospital, Gokdere Sokak 3/10, 06550, Yukari Ayranci/Ankara/Turkey. e-mail: giyas67@hotmail.com

\section{Commentary}

The authors have documented that a single posterior approach to correct both anterior and posterior lumbar column injuries can be successfully carried out.

The operation in Cases 1, 2, 6, and 7 appears to be a good choice for such injuries. But in Cases 3, 4, 5, and 8 , the patients were neurologically intact. And in one (Case 5), the canal compromise was only $30 \%$. We would not have operated on these patients. Proper positioning on a bed (back extended) for a few days would be all that is needed. The recent reviews by Rechtine ${ }^{1-3)}$ have documented the advantage of conservative treatment for that group.

Case 1 is the best example for the need of their operation and we have done exactly the same kind of procedure. It does work well. The authors' description of the techniques needs to be kept in mind if one's practice includes many trauma cases.

\section{References}

1) Hartman MB, Chrin AM, Rechtine GR: Non-operative treatment of thoracolumbar fractures. Paraplegia 33: 73-76, 1995

2) Rechtine GR 2nd: Nonoperative management and treatment of spinal injuries. Spine 31(11 Suppl): S22-27; discussion S36, 2006 (review)

3) Rechtine GR 2nd, Cahill D, Chrin AM: Treatment of thoracolumbar trauma: comparison of complications of operative versus nonoperative treatment. J Spinal Disord 12: 406-409, 1999

Thomas B. DuCKER, M.D., F.A.C.S. Department of Neurosurgery Johns Hopkins University Annapolis, Maryland, U.S.A.

This is an interesting paper showing stabilization of the three columns only through the posterior approach. In spinal trauma patients with multiple injuries, we hesitate to perform invasive surgery such as combined anterior and posterior approaches. The authors have introduced a smart way to stabilize the three columns through only the posterior approach using distractable cages. I look forward to the next report of a larger number of cases with longer follow up.

Masakazu TAKAYASU, M.D. Department of Neurological Surgery Aichi Medical University Aichi, Japan 